\title{
A Fuzzy Inference System for Maize Plant Yield Prediction
}

\author{
Olajide Blessing Olajide, Odeniyi Olufemi Ayodeji, Olabiyi Olatunji Coker, Adewale Joseph Adekunle, \\ Yakubani Yakubu
}

\begin{abstract}
Ascertaining infections in maize plants is through observation of the crop plant for visual indications which a farmer is able to relate to specific diseases. The perception of the farmer is prone to human error which may sometimes link some symptoms to the wrong disease and could impact the application of suitable preventive and curable routines to combat the identified diseases. Hence, accurate identification of crop plant disease is of high importance to a farmer to aid response to diseases. The objective of this article is to apply fuzzy set and interpolation technique to develop an expert system to carry out field-based identification and yield forecast for the maize plant. For this study, some associated factors were recognized for maize plant diseases and confirmed by a professional Botanists. For this study, a number of associated factors were identified for maize plant diseases and validated by experienced Botanists. Further to this, triangular membership functions was used to develop the fuzzy inference system model following the preprocessing of identified factors and related output. 32 inferred rules were formulated using IF-THEN statements which adopted the values of the factors as antecedent and the yield of maize plant as the consequent part of each rule for classification of the yield of maize plant. The Fuzzy model was simulated for each of the identified five factors. The simulation results showed that the risk factors identified; black moldy growth on kernels and ears, blights on leaves, rotten cobs, infected husks and black kernels and seed decay have noticeable influence on the maize plant yield if timely remedy is not administered. The study established that the utilisation of fuzzy technique is helpful to appraise the yield of maize such that the lesser the manifestation of identified associated features then the higher the yield of the maize plant.
\end{abstract}

Keywords: disease, fuzzy logic, maize, yield.

\section{INTRODUCTION}

$\mathrm{M}$ aize (Zea mays L.) is a main cereal crop cultivated commonly around the world and positioned third in production after wheat and rice [1];[2]. It contains nutritional elements; vitamin A, C and E, carbohydrates, essential minerals, $9 \%$ protein, dietary

Manuscript received on September 10, 2021.

Revised Manuscript received on September 13, 2021.

Manuscript published on September 30, 2021.

*Correspondence Author olajideblessing55@gmail.com

Odeniyi Olufemi Ayodeji, Osun State College of Technology, Esa Oke, Nigeria. Email: olufemiodeniyi@gmail.com

Olabiyi Olatunji Coker, Federal University Wukari, Nigeria. Email: cokerolabiyi@gmail.com

Adewale Joseph Adekunle, Osun State College of Technology, Esa Oke, Nigeria. Email: joekunleadewale@gmail.com

Yakubani Yakubu, Federal University Wukari, Nigeria. Email: yakubuyakubani@gmail.com

(c) The Authors. Published by Blue Eyes Intelligence Engineering and Sciences Publication (BEIESP). This is an open access article under the CC BY-NC-ND license (http://creativecommons.org/licenses/by-nc-nd/4.0/)
Olajide Blessing Olajide*, Federal University Wukari, Nigeria. Email:

fibre and calories which are energy giving nutrients [3]. Maize is significant as a primary food in sub-Saharan Africa (SSA) as it affords food and income to over 300 million resource-poor smallholder farmers [4]. Identifying diseases in plants is through observation of asymptotic attributes which an agricultural expert is able to relay to particular diseases in the plant. In the instances, where experts are not accessible, other approaches for obtaining field-based diagnoses are encouraged [5]. An expert system is required to fill the gap in this scenario. The expert system has the capability of detecting disease earlier in ailing plant based on the knowledge bank that has been captured in it. This has consequences on the promptness and efficacy of interventions that can be introduced to the maize crop. Most expert systems utilize fuzzy inference methodology which is a basic act of incorporating structured human cognition into feasible algorithms that constitutes fuzzy models, which are one of the soft computing tools. Expert system over the years have its application in resolving the problem of inaccuracy and indecision, so as to improve tractability, robustness and cost-effective solutions for real world complications [6]. Consequence to the nutritional and economic worth of the maize crop, it is remarkable to reference the fact that diseases commonness on maize plantations is fast becoming an hinderance to farmer's pursuit for a bountiful yield. Hence, there is a need for an expert system for the classification of the yield of maize plant to allow efficacy in maize diseases control in order to enhance higher productivity. Therefore, this research adopted fuzzy inference for the formulation of a classification model which was used to detect maize plant disease based on a number of factors associated with the yield of maize.

\section{LITERATURE REVIEW}

Plant suffers from various diseases during their life span at any stage of growth. For farmers disease management is a critical matter which needs an immediate attention. Many researchers contributed in advancing the current expert systems, among which are the following works: [7] applied deep learning for the processing of images of cassava plant for the detection of plant diseases. The study collected a dataset of cassava diseases images taken at a field in Tanzania. The images were analysed using an assignment leaning to train a deep convolutional neural network to identify 3 diseases and 2 types of pest damages. The superlative model attained a wide-ranging precision of 93\% for data not applied in the training procedure.

Published By:

Blue Eyes Intelligence Engineering

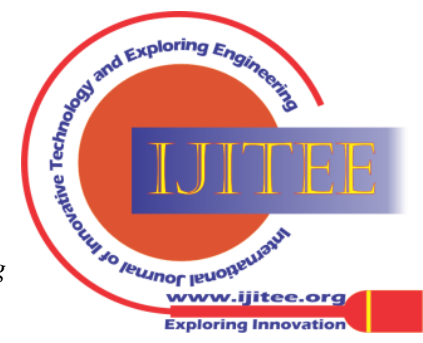




\section{A Fuzzy Inference System for Maize Plant Yield Prediction}

The results also showed that the transfer learning strategy for image identification of field images offers a swift, inexpensive, and easily deployable tactic for digital plant disease identification. [8] developed a web-based inference system to perceive and identify the leaf diseases of cereals in Punjabi Language. The features of leaf diseases were extracted and were used to formulate the diagnosis model by adopting IF-THEN rules from the features. The system was designed using unified modelling language (UML) tools such as use case diagrams and data flow diagrams. The model was integrated into a web-based implementation of the system using PHP and SQL. [9] developed an expert's system for the diagnosis of cassava plant diseases. The study identified a number of symptoms that were taken from the leaves, stems and roots of cassava plant required for the diagnosis of 3 different cassava plant diseases. The study adopted the use of 3 triangular membership functions to formulate the 3 symptoms of each diseases identified alongside the level of disease risk. The Fuzzy Logic model was formulated using the MATLAB Fuzzy Logic Toolbox while the inference rules were constructed as IF-THEN statements combining the values of each identified symptom. The model recorded an accuracy of $71.4 \%$ during model validation. [10] developed an inference system for identifying distinct coffee plant diseases. The inference system used are fuzzy logic, decision tree and hierarchical classification. Data about coffee, its symptoms, and its disease was mined from human expert and then converted into a decision tree. It lead to the development of fuzzy logic-based expert systems. From the experiments, precision of the system was about $85 \%$. Based on the precision, it was determined that its deployment will coffee farmers in identifying coffee plants diseases earlier. [11] developed an expert system for diagnosing poultry diseases. The study recognised the features that were applicable for evaluating the presence of diseases among poultry animals from experts via interviews. The information about the relationship between the features was established using IFTHEN rules to create antecedent and consequent rules required for the analysis of diseases among poultry. The expert system was designed using block diagrams following which it was implemented using the Visual Prolog software.

\section{METHODOLOGY}

In this study, five factors were identified which have a relative relationship with the classification of the severity of diseases affecting the maize plant. The five factors includes; presence of black mould growth on the kernels and ears of the maize plant, presence of blights on the leaves of the maize plant, presence of rots on the cobs of the maize plant, presence of infected husks and black kernels of the maize plant and presence of decay on the seeds of the maize plant. Crisp values were used to define the labels of each factor assessed as a way of quantifying the response to each factor. Then, each crisp value was assigned a linguistic value for which each fuzzy membership function was required to be formulated. It was determined that the presence of such factors increased the severity of maize plant disease while the absence of such factors reduced the severity of the maize plant disease. It was defined using 2 linguistic values namely: Yes and No which were assigned crisp values of 0 and 1 respectively. The severity of maize plant was classified into 4 linguistic variables, namely: None, Low, Moderate and High with crisp values of $0,1,2$, and 3 respectively. Following the identification of the variables that were proposed for this study, the membership function that was used to formulate the fuzzy inference system model was determined. The Block diagram of the development process of the fuzzy inference system model for the maize plant yield is shown in Figure 1. The diagram shows the various stages taken to actualise the development of the fuzzy inference system model for the prediction of maize plant yield. The process starts with the Botanist supplying expert information, which the knowledge engineer imbibes to populate the knowledge base. Then the developed fuzzy rules in the inference engine is used to test the system for conformity to the expert information supply. Then, the nonexpert farmer can have access to the fuzzy inference system model user interface.

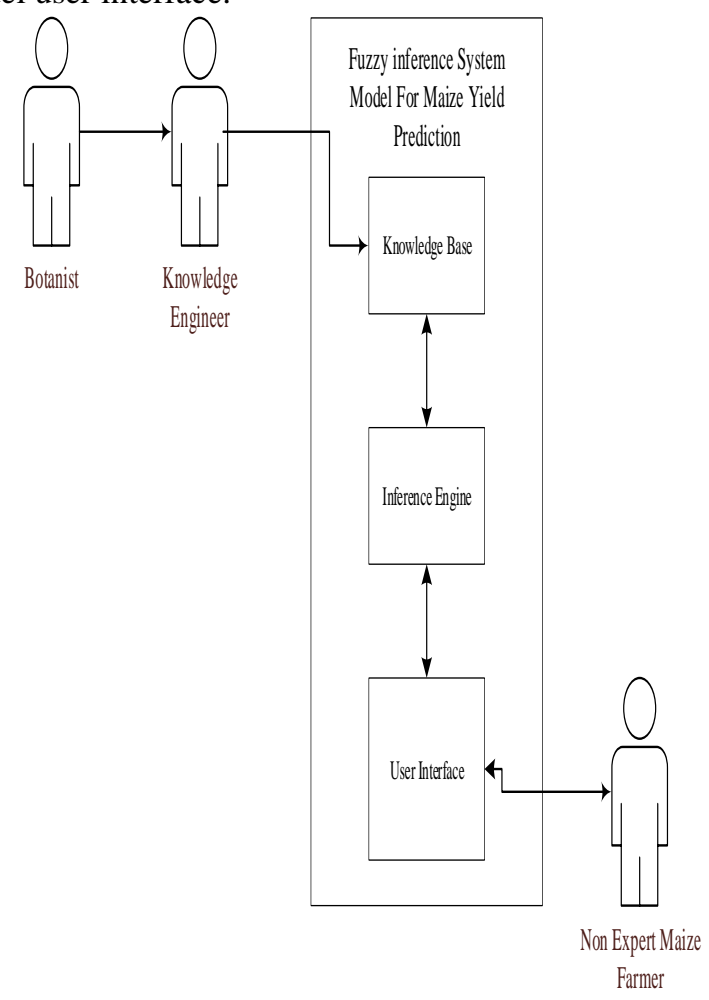

Fig. 1: Block Diagram of the Development Stages of the Maize Yield Fuzzy Inference System Model A. Fuzzy Logic Model Formulation for Severity of Disease

For the purpose of developing a classification model for severity of disease affecting maize plant using fuzzy logic theory, each factor identified was fuzzified using a triangular membership function. The triangular membership function required the provision of 3 parameters which consisted of the left-hand base of triangle (a), the central apex of the triangle (b) and the right-hand base of the triangle (c). The values (a, b, c) of the triangular membership function corresponded to an interval of $a \leq$ $b \leq c$ such that the parameters are numeric valued.

Published By:

Blue Eyes Intelligence Engineering

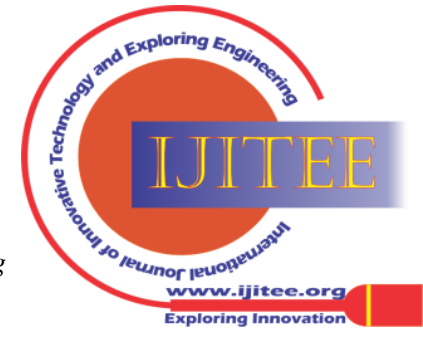


The interval of this parameter was used to define the crisp interval within which each crisp value required for calling the linguistic variable was assigned. As a result of this, since there were two linguistic variables defined for each factor identified then there were two triangular membership functions such that one was assigned to each linguistic variable identified for each risk factor as appropriate. Therefore, two triangular membership functions were formulated for each factor that was identified in this study based on the mathematical expression in equation (1). The expression shows how the triangular membership function was used to formulate the label of a variable called variable_label by fitting a numerical value $x$ into a crisp interval of (a, b, c).

$$
\begin{gathered}
\text { Variable_label }(x ; a, b, c) \\
0 ; x \leq a \\
\frac{x-a}{b-a} ; a<x \leq b \\
\frac{c-x}{c-b} ; b<x \leq c \\
0 ; x>c
\end{gathered}
$$

Using two triangular membership functions, the labels of the identified factors were formulated using the crisp intervals of $(-0.5,0.5)$ and $(0.5,1.5)$ to model the linguistic variables for 0 and 1 respectively such that they are the center $b$ of each interval as shown in Table 1 .

Table- I: Description of Crisp Intervals used during Fuzzy Model Formulation

\begin{tabular}{lllll}
\hline $\begin{array}{l}\text { Crisp } \\
\text { Value }\end{array}$ & Interval & $\mathbf{A}$ & $\mathbf{B}$ & $\mathbf{C}$ \\
\hline $\mathbf{0}$ & $(-0.5$, & -0.5 & 0 & 0.5 \\
$\mathbf{1}$ & $0.5)$ & & & \\
& $(0.5,1.5)$ & 0.5 & 1 & 1.5 \\
$\mathbf{2}$ & $(1.5,2.5)$ & 1.5 & 2 & 2.5 \\
\hline
\end{tabular}

\section{B. Fuzzification of the classification of severity of maize plant disease}

Following the identification and the fuzzification of the factors of severity of maize plant disease, there was a need to formulate the target variable that was used to define the classification of severity of maize plant disease. The triangular membership function was used to formulate the fuzzy logic model for the target variable by assigning crisp values of $0,1,2$ and 3 to the target class labels, namely: None, Low, Moderate and High using the intervals ( -0.5 ,
0.5), (0.5, 1.5), (1.5, 2.5) and (2.5, 3.5) respectively Therefore, four (4) triangular membership functions were used to formulate the fuzzy logic model required to describe the 4 labels of the target class that was used to describe the suitability of land using the identified crisp as shown in Table 2.

Table- II: Formulation of Classification of Severity of

\begin{tabular}{|c|c|c|c|c|}
\hline $\begin{array}{l}\text { Target } \\
\text { Class }\end{array}$ & Interval & $\mathrm{A}$ & $\mathrm{b}$ & $\mathrm{C}$ \\
\hline None & $\begin{array}{l}(-0.5 \\
0.5)\end{array}$ & -0.5 & 0 & 0.5 \\
\hline Low & $\begin{array}{l}(0.5, \\
1.5)\end{array}$ & 0.5 & 1 & 1.5 \\
\hline Moderate & $\begin{array}{l}(1.5, \\
2.5)\end{array}$ & 1.5 & 2 & 2.5 \\
\hline High & $\begin{array}{l}(2.5, \\
3.5)\end{array}$ & 2.5 & 3 & 3.5 \\
\hline
\end{tabular}
Maize Plant Disease

The relationship between the factors and severity of maize plant disease was established using the fuzzy inference system. To implement the fuzzy inference system, rules were inferred from the experts in order to determine the relationship between the factors identified and severity of maize plant disease. In order to construct the knowledge base of the classification model using fuzzy logic, a number of IF-THEN rules were used by combining the factors as the precedence while the severity of maize plant disease was used as the consequent variable. Using the factors that were identified for assessing severity of diseases affecting the maize plant, the process of inference rule generation usually follows the fuzzification process. A typical rule that can be inferred is as follows:

IF(Black Moldy growth and Kernels on Ear = "No") AND (Blight on Leaves = "No") AND (Rotten Cobs = "No") AND (Infected Husks and Black Kernel = "No") AND $($ Seed Decay = "No") THEN (Severity of Disease ="Low"). The number of rules that were required to be formulated for the fuzzy model were estimated from the product of the number of linguistic variable for each variable. Therefore, since each of the factors considered has two linguistic variables each. Therefore, the total number of rules was 32 rules. The 32 rules inferred for the inference engine are presented in Table 3

\begin{tabular}{|c|c|c|c|c|c|c|}
\hline Rule\# & $\begin{array}{l}\text { Black Moldy growth on } \\
\text { Kernels and Ears }\end{array}$ & $\begin{array}{l}\text { Blight on } \\
\text { Leaves }\end{array}$ & $\begin{array}{l}\text { Rotten } \\
\text { Cobs }\end{array}$ & $\begin{array}{c}\text { Infected Husks and } \\
\text { Black Kernels }\end{array}$ & $\begin{array}{l}\text { Decayed } \\
\text { Seeds }\end{array}$ & $\begin{array}{c}\text { Severity of } \\
\text { Maize Plant } \\
\text { Disease } \\
\end{array}$ \\
\hline 1 & Yes & Yes & Yes & Yes & Yes & No Yield \\
\hline 2 & Yes & Yes & Yes & Yes & No & Low Yield \\
\hline 3 & Yes & Yes & Yes & No & Yes & Low Yield \\
\hline 5 & Yes & Yes & No & Yes & Yes & Low Yield \\
\hline 6 & Yes & Yes & No & Yes & No & Low Yield \\
\hline 7 & Yes & Yes & No & No & Yes & Low Yield \\
\hline
\end{tabular}

Table- III: Inference rules for the Inference System Model of Maize Plant Yield

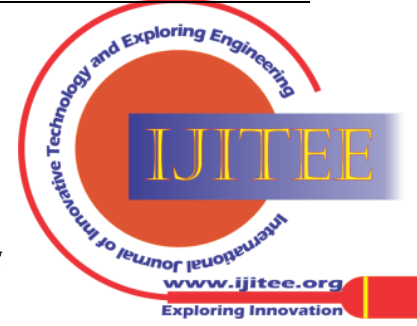


A Fuzzy Inference System for Maize Plant Yield Prediction

\begin{tabular}{|c|c|c|c|c|c|c|}
\hline 8 & Yes & Yes & No & No & No & $\begin{array}{c}\text { Moderate } \\
\text { Yield }\end{array}$ \\
\hline 9 & Yes & No & Yes & Yes & Yes & Low Yield \\
\hline 10 & Yes & No & Yes & Yes & No & Low Yield \\
\hline 11 & Yes & No & Yes & No & Yes & Low Yield \\
\hline 12 & Yes & No & Yes & No & No & $\begin{array}{c}\text { Moderate } \\
\text { Yield }\end{array}$ \\
\hline 13 & Yes & No & No & Yes & Yes & Low Yield \\
\hline 14 & Yes & No & No & Yes & No & $\begin{array}{c}\text { Moderate } \\
\text { Yield }\end{array}$ \\
\hline 15 & Yes & No & No & No & Yes & $\begin{array}{l}\text { Moderate } \\
\text { Yield }\end{array}$ \\
\hline 16 & Yes & No & No & No & No & High Yield \\
\hline 17 & No & Yes & Yes & Yes & Yes & Low Yield \\
\hline 18 & No & Yes & Yes & Yes & No & Low Yield \\
\hline 19 & No & Yes & Yes & No & Yes & Low Yield \\
\hline 20 & No & Yes & Yes & No & No & $\begin{array}{c}\text { Moderate } \\
\text { Yield }\end{array}$ \\
\hline 21 & No & Yes & No & Yes & Yes & Low Yield \\
\hline 22 & No & Yes & No & Yes & No & $\begin{array}{c}\text { Moderate } \\
\text { Yield }\end{array}$ \\
\hline 23 & No & Yes & No & No & Yes & $\begin{array}{c}\text { Moderate } \\
\text { Yield }\end{array}$ \\
\hline 24 & No & Yes & No & No & No & High Yield \\
\hline 25 & No & No & Yes & Yes & Yes & Low Yield \\
\hline 26 & No & No & Yes & Yes & No & $\begin{array}{c}\text { Moderate } \\
\text { Yield }\end{array}$ \\
\hline 27 & No & No & Yes & No & Yes & $\begin{array}{c}\text { Moderate } \\
\text { Yield }\end{array}$ \\
\hline 28 & No & No & Yes & No & No & High Yield \\
\hline 29 & No & No & No & Yes & Yes & $\begin{array}{c}\text { Moderate } \\
\text { Yield }\end{array}$ \\
\hline 30 & No & No & No & Yes & No & High Yield \\
\hline 31 & No & No & No & No & Yes & High Yield \\
\hline 32 & No & No & No & No & No & High Yield \\
\hline
\end{tabular}

The research was simulated using MATLAB of version R2015b. Five primary GUI tools (Elements of the MATLAB Fuzzy Logic System) for constructing, editing, and observing fuzzy inference systems were hired to realize the simulation;

i. Fuzzy Inference System (FIS) Editor; handles the high-level issues for the system: it was used to define the variable identifiers of input and output for the proposed model. For this study, five input variable identifiers and one output variable identifier were defined.

ii. Membership Function Editor; was used to formulate all linguistic variables defined for the inputs and output variable. For this study, two membership functions were used to formulate each input variable with two linguistic variables while four membership functions were used to creat the linguistic variables namely: None, Low, Moderate and High for the output variable.

iii. Rule Editor; was used for editing the various inference rules that defined the behaviour of the system using a set of IF-THEN statements which combined the identified factors with the labels of the severity of disease affecting maize plant. In this study, 32 rules were constructed using the IF-THEN based on the number of possible combinations of the linguistic variables of input variables needed for determining their respective severity of disease affecting the maize plant.

iv. Rule Viewer; It shows pictorially the active rules and individual membership function shapes are influencing the results. This interface was need for testing the validity of the consistency of the fuzzy inference system model based on the inferred rules constructed for detecting the severity of diseases affecting maize plants.

\section{RESULTS AND DISCUSSIONS}

Two triangular membership functions were used to develop the fuzzy inference system model for the labels of each risk factors with centres 0 and 1 for yes and no respectively. Also, the allocation of the values was done using the increasing effect of the labels of the identified disease features used in this study. Therefore, the results of the mathematical representation of the fuzzy logic model formulation using the triangular membership function for each of the labels is presented in equation 2, 3, 4, 5, 6 and 7.

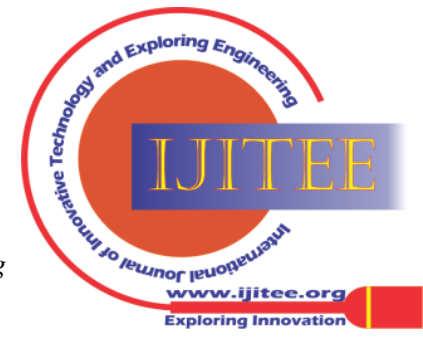




$$
\begin{aligned}
& \text { Crisp - label_yes }(x ;-0.5,0,0.5) \\
= & \left\{\begin{array}{r}
0 ; x \leq-0.5 \\
\frac{x+0.5}{0.5} ;-0.5<x \leq 0 \\
\frac{0.5-x}{0.5} ; 0<x \leq 0.5 \\
0 ; x>0.5
\end{array}\right. \\
& \text { Crisp - label_no( } x ; 0.5,1,1.5) \\
0 ; x \leq 0.5 & \left\{\begin{array}{c}
\frac{x-0.5}{0.5} ; 0.5<x \leq 1 \\
\frac{1.5-x}{0.5} ; 1<x \leq 1.5 \\
0 ; x>1.5
\end{array}\right.
\end{aligned}
$$

Also, the classification of the yield of maize plant was classified into 4 linguistic variables, namely: No risk, Low risk, Moderate risk and High risk using crisp values with centers of $0,1,2$ and 3 respectively. Using the 4 triangular membership functions stated in equations (2) to (5), the linguistic variables of the yield of maize plant was formulated.

$$
\begin{aligned}
& \text { Crisp - no_risk }(x ;-0.5,0,0.5) \\
& =\left\{\begin{array}{c}
0 ; x \leq-0.5 \\
\frac{x+0.5}{0.5} ;-0.5<x \leq 0 \\
\frac{0.5-x}{0.5} ; 0<x \leq 0.5 \\
0 ; x>0.5
\end{array}\right. \\
& \text { Crisp - low_risk }(x ; 0.5,1,1.5) \\
& =\left\{\begin{array}{c}
0 ; x \leq 0.5 \\
\frac{x-0.5}{0.5} ; 0.5<x \leq 1 \\
\frac{1.5-x}{0.5} ; 1<x \leq 1.5 \\
0 ; x>1.5
\end{array}\right. \\
& \text { Crisp - moderate_risk }(x ; 1.5,2,2.5) \\
& =\left\{\begin{array}{c}
0 ; x \leq 1.5 \\
\frac{x-1.5}{0.5} ; 1.5<x \leq 2
\end{array}\right. \\
& =\left\{\begin{array}{c}
\frac{2.5-x}{0.5} ; 2<x \leq 2.5 \\
0 ; x>2.5
\end{array}\right. \\
& \text { Crisp - high_risk }(x ; 2.5,3,3.5) \\
& =\left\{\begin{array}{c}
0 ; x \leq 2.5 \\
\frac{x-2.5}{0.5} ; 2.5<x \leq 3 \\
\frac{3.5-x}{0.5} ; 3<x \leq 3.5 \\
0 ; x>3.5
\end{array}\right.
\end{aligned}
$$

\section{A. Simulation Results of the Inference System Model for Yield of Maize Plant}

The study identified 5 factors required for the classification of the yield of maize plant. Each factor was defined using two linguistic variables for which central crisp values were assigned based on the association with the classification of the yield of maize plant. The higher the association of the linguistic variable then the higher the central crisp values assigned. In all, 5 factors were identified to be associated with the yield of maize plant.The presence of factors (Yes) was an indication of the presence of an infection which reduces the yield of the maize plant while the absence of factors (No) was an indication of the absence of an infection which increases the yield of the maize plant. Each factor were defined using two linguistic variables, namely: Yes and No with crisp intervals of [-0.5, 0.5] and [0.5 1.5] with centers 0 and 1 respectively while four linguistic variables, namely: No yield, Low yield, Moderate yield and High yield were used to define the yield of maize plant using centers $0,1,2$ and 3 respectively. Therefore, two triangular membership functions were used to formulate the input factors while four triangular membership functions were applied to generate the target yield of maize plant. For the purpose of establishing a relationship between the identified factors identified, 32 rules were inferred from the experts in order to actualise the relationship between the disease features identified and classification of the yield of the maize plant. In order to construct the knowledge base of the classification model using fuzzy logic, a number of IFTHEN rules were used by combining the factors as the precedence while the classification of the yield of the maize plant was used as the consequent variable. Using the risk factors that were identified for assessing the classification of the yield of the maize plant, the process of inference rule generation was achieved. Figure 2, 3, 4 and 5 shows snapshot of the developed fuzzy logic MATLAB simulink model for classification of maize plant yield.

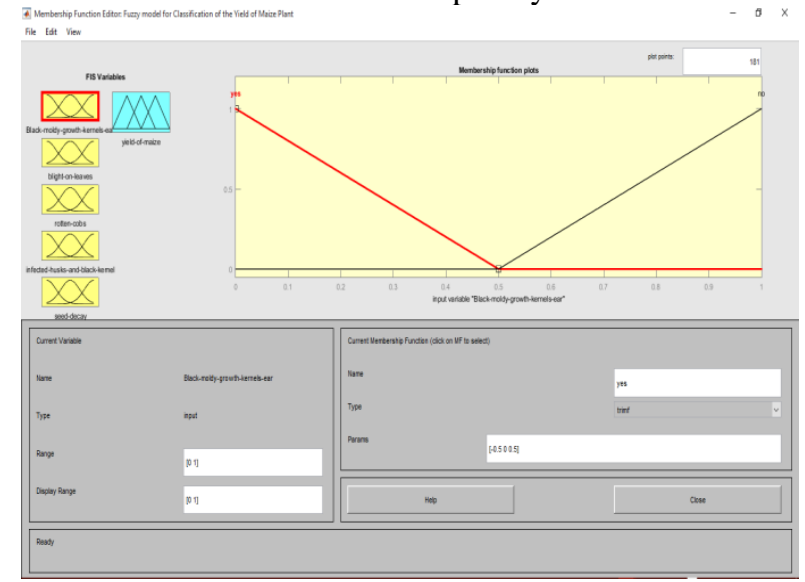

Fig. 2: Fuzzification of Factors in Maize Plant

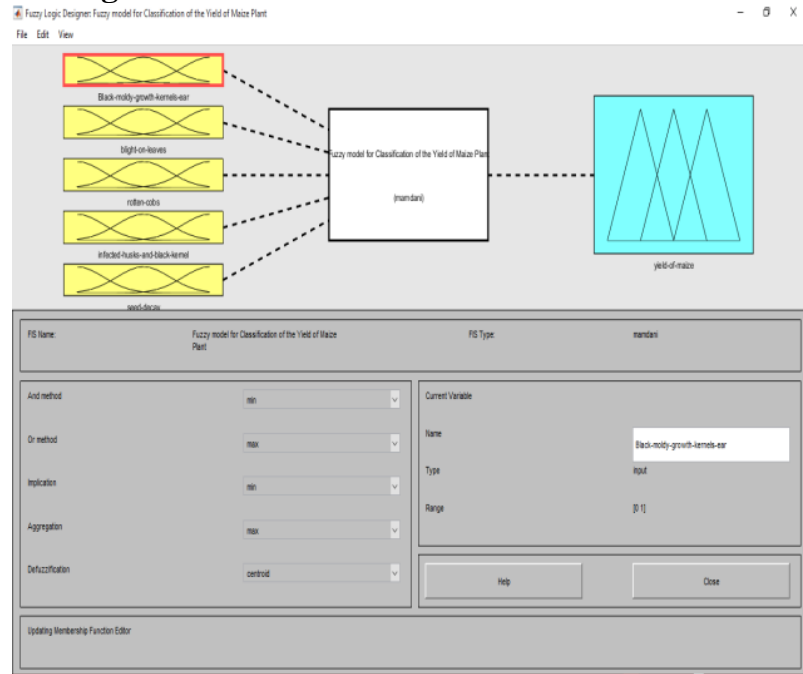

Fig. 3: Importing. fis File for Classification of the Yield of maize plant

Published By:

Blue Eyes Intelligence Engineering and Sciences Publication

(C) Copyright: All rights reserved.

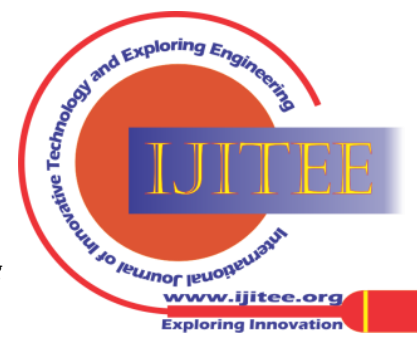




\section{A Fuzzy Inference System for Maize Plant Yield Prediction}

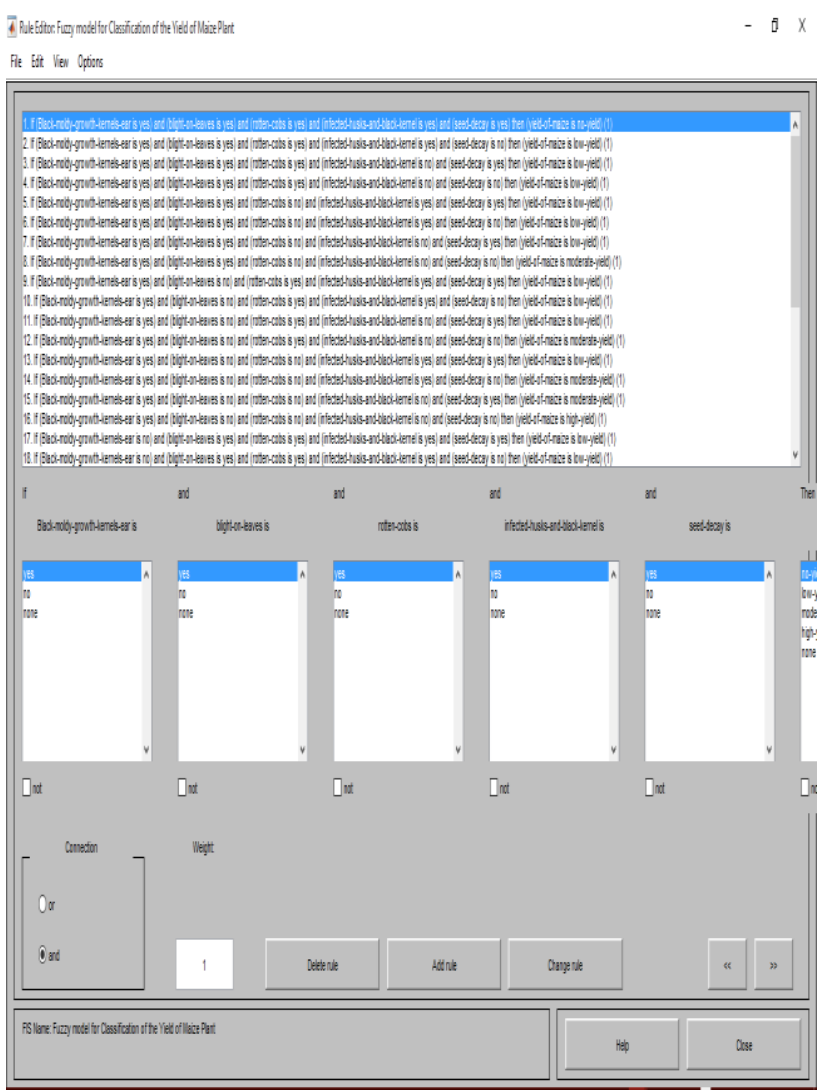

Fig. 4: The Inferred Rules located in the Fuzzy Inference Engine

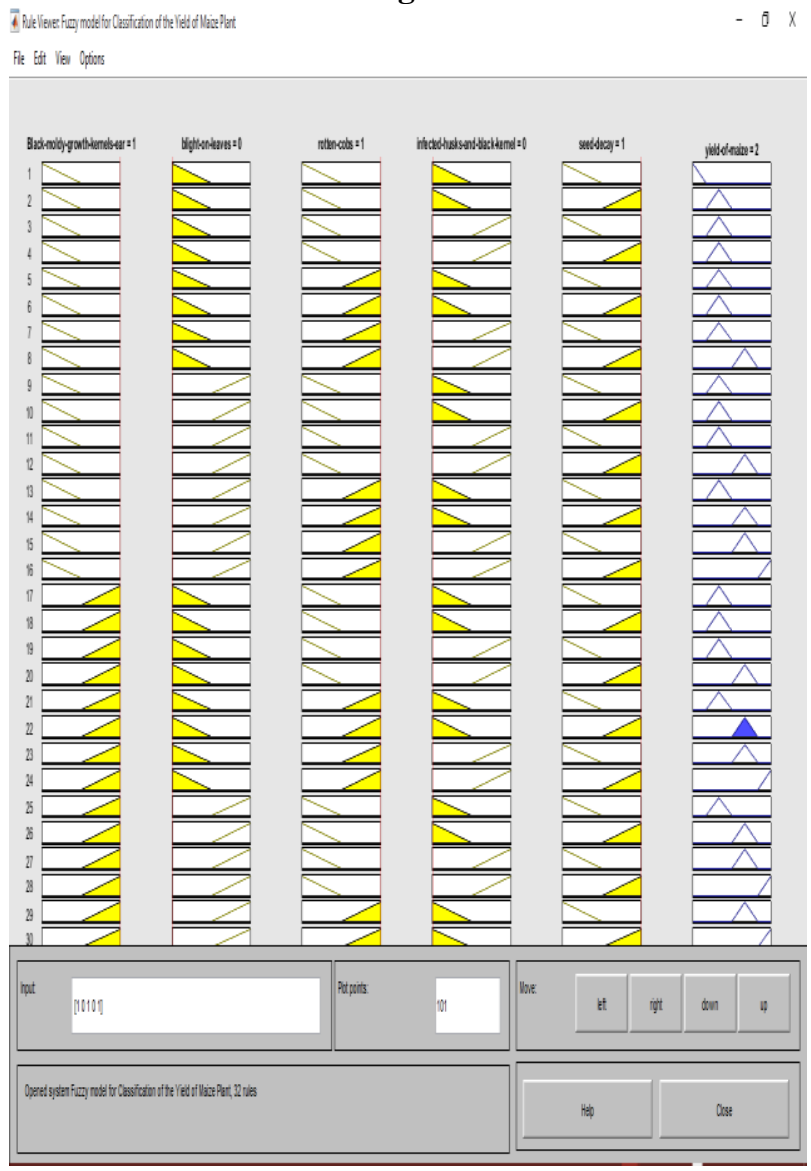

Fig. 5: Testing the Validity of the Inference Engine

\section{B. Discussion of Results}

The study identified 5 factors required for the classification of the yield of maize plant. Each factor was defined using 2 linguistic variables for which central crisp values were assigned based on the association with the classification of the yield of maize plant. The higher the association of the linguistic variable then the higher the central crisp values assigned. In all, 5 factors were identified to be associated with the yield of maize plant. The presence of factors (Yes) was an indication of the presence of an infection which reduces the yield of the maize plant while the absence of factors (No) was an indication of the absence of an infection which increases the yield of the maize plant. Each factor were defined using 2 linguistic variables, namely: Yes and No with crisp intervals of [-0.5, 0.5] and [0.5 1.5] with centers 0 and 1 respectively while 4 linguistic variables, namely: No yield, Low yield, Moderate yield and High yield were used to define the yield of maize plant using centers 0 , 1,2 and 3 respectively. Therefore, 2 triangular membership functions were used to generate the input factors while 4 triangular membership functions were used to generate the target yield of maize plant. For the purpose of establishing a relationship between the identified factors identified, 32 rules were inferred from the experts in order to determine the relationship between the risk factors identified and classification of the yield of the maize plant. In order to construct the knowledge base of the classification model using fuzzy logic, a number of IF-THEN rules were used by combining the factors as the precedence while the classification of the yield of the maize plant was used as the consequent variable. Using the risk factors that were identified for assessing the classification of the yield of the maize plant, the process of inference rule generation was achieved.

\section{CONCLUSION}

This study developed a fuzzy inference-based system model for the classification of the yield of maize plant in order to increase the productivity of the maize plant. The study concluded that the physical damage made on the plant by pests could be used to estimate the yield of maize such that the lesser the presence of such factors then the higher the yield of the maize plant. The study also concluded that the five related factors identified were black moldy growth on kernels and ears, blights on leaves, rotten cobs, infected husks and black kernels and seed decay. Two triangular membership functions were suitable for the generation of the linguistic variables of the factors, namely: yes and no while the marked yield was generated using four triangular membership functions for the linguistic variables no yield, low yield, moderate yield and high yield. The 32 inferred rules were formulated using IF-THEN statements which adopted the values of the factors as antecedent and the yield as consequent part of each rule. The developed fuzzy logic model was simulated to demonstrate its capabilities in predicting the yield of maize plant. This study also, prescribe for further research to be carried out by agriculturists in the identification of other important factors that are associated with the yield of the maize plant. This would increase the productivity of the crop and in essence contribute to the value of the National economy.

Published By:

Blue Eyes Intelligence Engineering

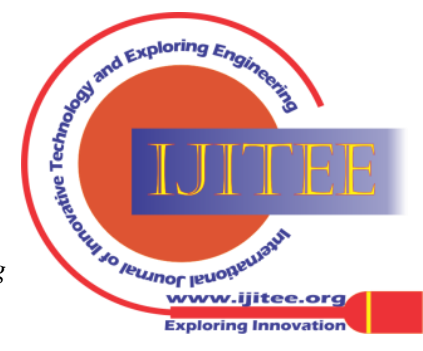




\section{REFERENCES}

1. Vinaya M. And Dhumale N. R (2018): "Leaf Disease Detection Using Fuzzy Logic", Internation Journal of Innovative Research in Science, Engineering and Technology, 7(6): 6801-6807.

2. Abdurrahim A., Ibrahim Y. And Remzzi E. (2016): "Flood Forecasting Using Transboundary Data with Fuzzy Inference System: The Maritza (Meric) River", Journal of Natural Harzards and Earth System Sciences, DOI 10.5194/nhess.2016-86, 1-17.

3. Sachin D. and Kharade (2015): "Plant Disease Detection Using Image Processing", International Conference on Computing Comunication Control and Automation, 201-215.

4. Pramod S., Landge and Maridal L. (2013): "Automatic Detection and Classification of Plant Disease Through Image Processing", International Journal of Advance Research in Computer Science and Software Engineering, 3(7): 1110-1126.

5. Vidita T, Jignesh P and Chetan B. (2013): "Weather Based Plant Disease Forecasting Using Fuzzy Logic", in proceedings of Nirma University International Conference on Engineering (NUiCONE), DOI: 10.1109/NUiCONE 2013.6780173, 225-230.

6. Pasqual S. And Thorat S. (2019): "Early Detection of Grapes Disease Using Machine Learnign and ioT", Proceedings of Second International Conference on Cognitive Computing and Information Processing (CCIP), IEE, 1-5.

7. Ramcharan A., Peter C., Kelsee B. and Babuali A. (2017): "Using Transfer Learning for Image -Based Cassava Disease Detection”, Journal Frontiers in Plant Science, Technical Advances in Plant Sciences, 1-8

8. Kaur R. And Din S. (2016): "Web Based Expert System to Detect and Diagnose the Leaf Disease of Cereals in Punjabi Language", International Journal of Computer Science and Information Technology 7(4) 1771-1773.

9. Awoyelu I. And Adebisi R. O. (2015): “A Predictive Fuzzy Expert System for Diagnosis of Cassava Plant Diseases", Global Journal of Science Frontier Research, 15(5): 20-28.

10. Suharto D. Wahhyu A. Miranty L and Muhammad Y. (2013): "Expert System in Detecting Coffee Plant Diseases", International Journal of Electrical Energy 1(3) 156-162.

11. Olanloye D. and Yerokun O. (2018): "Design and Implementation of an Expert System for Diagnosing, Treatment and Management of Poultry Disease", FULafia Journal of Science and Technology 4(2): 87-93.

\section{AUTHORS PROFILE}

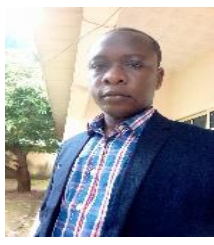

Olajide Blessing Olajide, has $\mathrm{PhD}$ in Computer Engineering. He is a member of Nigeria Society of Engineers NSE. He is also a member of Council for the Regulation of Engineering in Nigeria COREN. He has published several research articles in the field of fault-tolerant computing, artificial intelligence and machine learning. He is a lecturer in the Department of Computer Science, Federal University Wukari,

Nigeria.

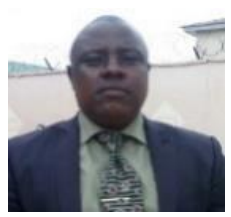

Odeniyi Olufemi Ayodeji, has $\mathrm{PhD}$ in Computer Science. He has published several research articles. $\mathrm{He}$ is currently working as a lecturer in the Department of Computer Science, Osun State College of Technology, Esa Oke, Nigeria.

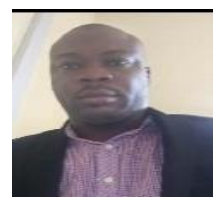

Olabiyi Olatunji Coker, has $\mathrm{PhD}$ in Ecology and Environmental Science, he has published several articles in the field of environmental biology, agriculture and ecology. He is currently a lecturer in the Department of Soil Science, Federal University Wukari, Nigeria.

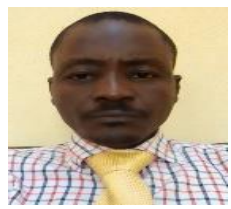

Adewale Joseph Adekunle, has an M. Sc in Computer Science and has published several computing research articles in international journals. $\mathrm{He}$ is currently a lecturer in the Department of Multimedia Technology, Osun State College of Technology, Esa Oke, Nigeria.

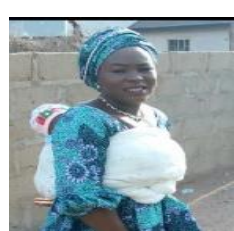

Yakubani Yakubu, has $M$. Sc in Computer Science, she has published several articles in the field of machine learning. She is specialised in modelling and simulation. She is currently a lecturer in the Department of Computer Science, Federal University Wukari, Nigeria.

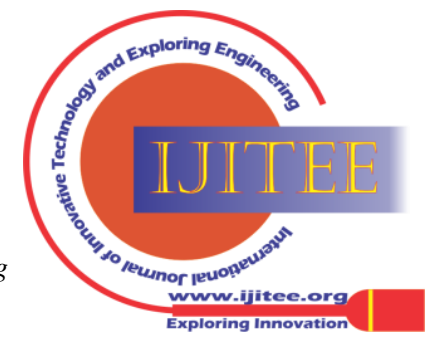

